A rapid review of the impact of quarantine and restricted environments on children's play and health outcomes.

Kelsey M. Graber, Elizabeth M. Byrne, Emily J. Goodacre, Natalie Kirby, Krishna Kulkarni, Christine O'Farrelly, and Paul G. Ramchandani

Faculty of Education, PEDAL Research Centre, University of Cambridge, Cambridge, UK

Conflicts of interest: No conflicts of interest to declare.

Funding declaration: All authors work at the PEDAL Research Centre at the University of Cambridge, which receives philanthropic funding from the LEGO Foundation. The funder played no part in the direction or execution of this research.

Note to readers of the pre-print: This report is intended to provide a summary and synthesis of existing literature regarding the impact of quarantine, isolation or other restrictive environments on children's play and health. The literature search was completed as a rapid review in order to make the results available to those developing further research or policies that may affect children in the wake of the COVID-19 pandemic.

We encourage open access peer review for this report in its pre-print stage. We particularly welcome feedback regarding the following questions:

1. Are there key studies (in published or grey literature), integral to this topic, that are not included in the current review?

2. Does the review provide a fair interpretation of the literature identified in this search?

Please direct all correspondence to Kelsey Graber at kg421@cam.ac.uk. 


\title{
A rapid review of the impact of quarantine and restricted environments on children's play and health outcomes.
}

Kelsey M. Graber, Elizabeth M. Byrne, Emily J. Goodacre, Natalie Kirby, Krishna Kulkarni, Christine O'Farrelly, and Paul G. Ramchandani

Faculty of Education, PEDAL Research Centre, University of Cambridge, Cambridge, UK

\begin{abstract}
In the wake of the current COVID-19 health crisis, there is uncertainty and concern about the impact this pandemic will have on children's health and educational outcomes. Play is a fundamental part of childhood and can be integral to children's health in moments of crisis. Due to severe lockdown regulations around the world, typical play experiences have needed to adapt to school and playground closures, changes to peer interactions, and social distancing. We undertook a rapid literature review of the impact of quarantine, isolation, or other restrictive environments on children's play and whether play may mitigate the adverse effects of such restrictions. Fifteen peer-reviewed studies were identified, spanning various environments in which children faced restriction, including hospitalisation, juvenile and immigration detention, and displacement to a refugee camp. We found that the literature provided evidence of changes in children's access to play under restrictive circumstances, but less conclusive inferences regarding changes in frequency of play behaviours. These studies also indicated ways in which play might support children going through periods of isolation or quarantine, via promoting coping, expression, sociability, and skill development, but critically lacked robust investigations of play as a mechanism or intervention target in mitigating the negative impacts of restriction during childhood. Studies pertaining to children in isolation due to infectious disease outbreaks were notably absent from the literature reviewed in this search. We present these findings from the literature followed by recommendations for further research that may better support children in this and future moments of crisis.
\end{abstract}




\section{Introduction}

The ongoing coronavirus (COVID-19) pandemic is a health crisis that is uniquely affecting members of the global community. In such moments of crisis, it is often vulnerable populations that are acutely affected, not only medically, but also socio-economically and psychologically (Berkman, 2008; Hutchins, Truman, Merlin, \& Redd, 2009). For children, this vulnerability may be reflected in their disease susceptibility, access to education, nutrition, socio-economic status, as well as physical and psychological safety within households (Armitage \& Nellums, 2020; Landrigan, 2005). There is also concern that health crises like COVID-19 can have hidden, yet potentially profound and long-lasting, impacts on children's health and education (Ramchandani, 2020).

As a universal crisis, virtually all children in all countries are being impacted by COVID-19 (United Nations, 2020). Social distancing and nation-wide lockdowns were instated throughout January-April 2020 in order to slow the transmission of the virus among populations after the declaration of COVID19 as a pandemic (Ren, 2020; World Health Organization, 2020). On 9 April 2020, UNICEF reported that 2.34 billion children and young people under the age of 18 live in one of the 186 countries with movement restrictions in place due to COVID-19, and $60 \%$ of children are living in one of the 82 countries experiencing a full (7\%) or partial (53\%) lockdown (Fore, 2020). Such restrictions include school closures, playground and public park closures, and restrictions around the frequency and amount of time people should spend out of their households with limited, if any, access to social and extended family networks. By consequence, there has been an unprecedented and global shift in where, when, how, and with whom play occurs.

There is good reason to take changes to children's play seriously. Emerging evidence suggests that prolonged school closure, home confinement, and social restriction during disease outbreak could have serious consequences for children's physical and mental health, highlighting the need for preventative support and early intervention for children facing social restrictions (Brooks et al., 2020; Guan et al., 2020; Holmes et al., 2020; Loades et al., 2020; Xie et al., 2020). For children living within these severe safety restrictions, play may be one of the most essential ways to attend to their health, development, and learning. The importance of play as a fundamental right of all children (UNCRC, 2013) as a way of maintaining semblances of normalcy and encouraging psychological and physical health has been highlighted in academic and advocacy contexts (e.g. Cohen, 2018; International Play Association, 2020; Nijhof et al., 2018; Yogman et al., 2018). In situations of crisis, play can help children to cope with stress, anxiety, and trauma associated with the emergency (Chatterjee, 2018) and can provide stability, normalcy, and enjoyment (International Play Association, 2017). It is of concern, therefore, that at a time of increased stress and worry within families and communities, children are also faced with shifts in or reduced access to play and the affordances it offers for their development and coping. Thus, it is important in this critical moment to better understand the connections between physical or environmental restrictions, children's play, and their health, development, and wellbeing.

\section{Rationale for this Review}

This review aimed to collate the available evidence as to whether quarantine and other forms of isolation have an impact on children's play, and secondly to investigate whether play might mitigate any adverse effects of quarantine or other forms of isolation on children's health and educational outcomes. We endeavoured not only to identify gaps in the research literature, but also to inform the foundations of policies that affect children during moments of crisis. 


\section{Research Questions}

Based on a review of research:

1) How do quarantine and related restricted environments* affect play ${ }^{\dagger}$ in children and young people?

2) In what ways might play and related activities mitigate the impact of quarantine and restriction on children/young people's health and education?

$*+$ See Appendix A for definitions of these terms.

\section{Methods}

We conducted a rapid review to quickly synthesise evidence on the topic of children's play under circumstances of restriction. We limited the number of databases searched and abbreviated the data extraction and synthesis strategies in accordance with accepted parameters for streamlining traditional review methodologies (Ganann, Ciliska, \& Thomas, 2010). Search terms relating to (A) the population of interest: children and young people; (B) quarantine and restricted environments; and (C) play and related activities were included. Appendix B provides full details for the search syntax.

Prior to commencing database searching, the review protocol was registered with the Open Science Framework (OSF) on 16 April 2020 as a means of engaging the academic community and soliciting feedback from key experts and organisations (www.osf.io/vajnk). We searched key databases covering psychology, education, and medical research: Psyclnfo, ERIC, and PubMed. We searched these databases between 21 March and 25 March 2020, filtering for English-language articles. All three databases were searched using the same search syntax (Appendix B).

Inclusion criteria for selected articles consisted of: peer-reviewed research reports, involving children and young people under age 18, participants experiencing quarantine or related restricted environments, assessment of (or collected data on) educational, developmental, or health related outcomes, and referencing play or related activities in relation to study concept. All articles were title and abstract screened for eligibility and results were double-screened to ensure adherence to criteria.

\section{Results}

Our search across the three databases yielded 5,897 papers published between 1980-2018, of which 12 met the inclusion criteria (see Figure 1). Handsearching provided an additional three papers for inclusion, totalling 15 studies. Study characteristics were extracted from the selected studies, and key messages and themes were identified via narrative synthesis. See Table 1 for a summary of the study characteristics and the corresponding reference numbers.

Most studies employed a qualitative methodology ( $n=11)$, with few quantitative $(n=3)$ and one mixed methods study. Studies were conducted in the USA ( $n=9)$, Canada $(n=2)$, and one study each from Australia, Ireland, Israel, Palestine, and South Africa. Participants' ages ranged from 5 months to 21 years, and sample sizes ranged from 1 to 295.

Studies were conducted in various types of restricted environments, including hospitals ( $n=7)$, juvenile detention centres $(n=4)$, immigration detention centres $(n=3)$, and refugee camps $(n=1)$. Our search 
did not find studies investigating restricted environment due to a disease outbreak. Of the studies that reported on duration, the length of time participants spent in restricted environments ranged from 48 hours to 330 days.

Play

We will first outline the different aspects of play that were described in the literature to contextualise the themes that were identified in the studies included in the review. Various play and play-related activities were identified, including sand play [4], puppet play [7], toy play [5], rule-based games [11], art $[6,13,14]$, reading $[9]$, writing $[9,14,15]$, and music $[1,10]$. One study involved a discussion of play opportunities in an immigration detention centre but did not provide specific information about specific play activities [8].

The role of play differed across the review studies: some used play as a tool $[10,11,13,15]$ (e.g. to administer and evaluate the success of an occupational therapy program [11]) while in others, play was the outcome of interest $[2,8,9,12]$ (e.g. measuring play frequency). In many papers play featured both as a research tool and outcome $[1,3-7,14]$ whereby play-based methods such as art $[6,14]$ or puppet play [7] were implemented, and the resulting playful performance or creation was studied as the outcome.

The following themes relating to children's play amidst restrictive conditions were identified: (1) access to play, (2) frequency of play behaviours, (3) play as a means of expression, (4) play to support social connectivity, (5) play to promote coping, and (6) play for skill development. These themes are explored within the context of our overarching research questions.

Research question 1: How do quarantine or restricted environments affect play in children and young people?

Nine studies addressed how restricted environments affect children's play, spanning various settings: hospital $[2,6,12]$, immigration detention $[3,4,8]$, juvenile detention $[9,15]$, and refugee camps [14]. One study [15] utilised play specifically as a means of data collection, while others considered play as an outcome of interest $[2,8,9,12]$. Four studies used play and related activities as both a method for collecting data as well as an outcome $[3,4,6,14]$. While one study used sand play [4], others used playrelated activities such as art or writing $[6,9,14,15]$. Three studies did not provide any specific information about the nature of the play (or related) activities $[2,3,8]$.

Studies discussed children's access to play in the context of children living either in immigration detention centres $[3,8]$ or refugee camps [14]. These restrictive environments were described as lacking in appropriate place space and resources, reporting that children were living in barren and dusty areas scattered with stones and razor wire, with minimal access to toys [14] or toys that were not age-appropriate [8]. Through interviews with parents and children, researchers reported that children in these settings experienced poor living conditions, remained idle and lacked social interaction for long periods, and could not play outdoors due to lack of weather-appropriate clothing [3]. Parents expressed how children were exposed to violence during confinement $[8,14]$, which diminished younger children's inclination to play and created an additional source of trauma. Disrupted access to play was also apparent in a study conducted within a hospital setting [6], where children reported a desire for more play space and resources while hospitalised for long periods. 
Through drawings and interviews, children indicated what was important to them while they were required to stay in a hospital environment: increased diversity of activities, more shared spaces, and more resources for play, games, and entertainment.

Studies of hospitalised children undergoing chemotherapy also examined the frequency of play behaviour $[2,12]$. One study found that play behaviours remained constant across six weeks of observation [2]; however, another study found that play behaviours fluctuated during medical isolation, with younger participants being less likely to experience these changes [12]. In this study, play-related activities encompassed a variety of behaviours across the broad age range of participants, including reading, writing, crafts, watching television, and completing schoolwork. Eight of 18 participants in the study showed changes in the frequency of their play during their hospital stay and periods of isolation.

Four studies emphasised play as a means of expression to gain insight into children's experiences of restriction or isolation $[4,9,14,15]$. In one study set in immigration detention [4] researchers engaged children in play, thinking it would provide better, more comfortable opportunities for children to share their experiences, as compared to a verbal interview. Their play behaviours contained themes of confinement and surveillance as well as violence and loss of protection, and notably lacked concepts of school or friends, which are usually associated with children's play. In a refugee camp [14], participants' drawings and written creations featured elements such as political resistance and violence, which represented their unique experience of living within that constrained environment. Two studies set in juvenile detention centres investigated engagement in reading and writing activities. They found the content of the expressive activities reflected participants' experiences of being detained, desires for freedom, and hopes for a future outside of detention $[9,15]$.

Two studies also indicated the social connectivity impacts of restriction on play and related activities $[6,9]$. Hospitalised children conveyed a desire for more social connection and interaction, evidenced by interviews with and drawings from the children themselves depicting people together, shared spaces, and accessible gardens or playgrounds. Children confined to their beds or rooms reported that they had few opportunities for socialising and expressed wanting access to technology that would allow for communication at a distance (e.g. a computer with a camera) [6]. In a case study of a young girl in juvenile detention, it was reported that her engagement in reading and letter-writing activities with others in the centre reflected her longing for social connection, and allowed her to form or foster relationships with others while experiencing isolation [9].

Research question 2: How might play mitigate the impact of quarantine or other restrictions on children's health and education?

We identified ten studies relevant to the question of how play might mitigate the effects of quarantine or restriction on children's outcomes. These studies were set in hospital $[1,5,6,7,10]$, juvenile detention $[9,11,13,15]$, and refugee camps [14].

We identified five papers that used play as a means of expression and play to promote coping in restricted environments $[1,7,10,14,15]$, highlighting ways in which play helped children express themselves and share their thoughts about restrictive situations. Linn et al. (1996 [7]) reported on therapeutic puppet play with a young bone marrow transplant patient in medical isolation. The play 
sessions were described as helping the child to share concerns and fears regarding confinement and abandonment and as an aid to coping with challenging aspects of his medical restrictions. Two studies looked at the use of music in hospital settings to help children to cope with the stress of prolonged hospitalisation [1,10]. Brodsky (1989 [1]) reported that when given the opportunity to engage with musical outlets, children wrote lyrics and sang about their personal circumstances in the hospital environment. The author suggested that children need to talk about their hospital experiences in order to cope with them, and that musical play enables patients to express feelings, feel a sense of control, and find moments of solace or hope. Similarly, Robb (2000 [10]) conducted an observational study exploring the use of music in hospitals to enhance children's coping. This study reported that engagement in music therapy helped to create a supportive environment within which children could be in control and expressive, proposing that such playful contexts allowed children to better cope with the stressors of the hospital setting.

Additionally, a qualitative study conducted in a refugee camp used writing and drawing as playful methods to explore children's experiences [14]. Through their creations, children shared that play offered a sense of agency, competence, and control over the restricted environment in which they were growing up. In addition to opportunities for coping with their restrictions in the camp, the participants were able to share their ideas of hope for their future and consider outcomes beyond their current circumstances. Finally, research regarding the content of detainees' playscripts in juvenile detention reported that girls were able to express their thoughts and desires for the future through playwriting, inferring that the creative process was used as an outlet for problem solving and perseverance [15].

One hospital-based study implemented an intervention to improve children's access to play through the installation of play cabinets to combat a lack of individualised, sterile play materials for children who had undergone bone marrow transplantation [5]. These young patients must be kept in a sterile, isolated environment for extended periods. The knowledge required for nurses to select ageappropriate toys for children and the time needed to sterilise the toys and engage the child in playful experiences were identified as potential barriers to children freely accessing play during hospital isolation. According to two vignettes of children's experiences with play cabinet materials, increasing access to play during required isolation allowed children to engage in more physical and mental activity, reduced boredom and loneliness, and engaged children in sharing feelings and decisionmaking regarding their environment and routine.

Three papers looked at mitigating the effects of restricted environments by using play to promote skill development $[5,11,13]$. One study used playful methods such as rule-based games, arts, and crafts as part of an occupational therapy training program to youth in juvenile detention centres [11]. The goal of the study was to promote the acquisition of life skills through playful methods including group games and discussions, worksheets, and craft activities. The facilitators selected play activities based on the belief that the limited opportunities that incarcerated youth have for play may increase feelings of isolation and hamper their development. Some participants communicated that the play activities allowed them to express their feelings, hear about others' situations, gain a better understanding of self, and encouraged them to think about making changes in their lives to improve their own outcomes. The authors suggested that these play activities promoted self-awareness and positive personal reflections [11]. Another study conducted in a juvenile detention facility focused on a 
programme to create an art mural that would promote communication, social, and manual skills [13]. Art teachers noted developments in skills that were taught as part of the programme, and the author suggested that fostering a creative skill set could facilitate learning in other academic areas, although this was not explicitly studied. Finally, in the study on the use of play cabinets in a hospital [5], toys were selected with the purpose of promoting personal, social, fine motor, language, and gross motor skills in order to allow each child to meet their developmental milestones despite restriction.

Four studies examined the use of play and related activities as a means of increasing social connectivity in restricted environments $[5,6,9,13]$. Two studies provide information about young people's social behaviours in juvenile detention, as they engaged in reading and letter-writing [9] and art activities [13]. In the case study of an adolescent girl, engaging in reading and writing activities were linked to perceived increases in social opportunities and connections [9]. In another study, participation in an art mural project was reported as providing young detainees with opportunities for socialisation and developing positive relationships with adults and peers [13]. In a hospital setting, Kuntz et al. (1996 [5]) stressed the importance of play (with nurses) for developing and maintaining children's social skills, and for preparing them for later discharge and return to a typical, non-restrictive setting. Similarly, Lambert et al. (2014 [6]) recognised that children not only sought social connection outside of the hospital, but were also eager for playful social interaction within the hospital community.

\section{Discussion}

This rapid review is the first to map literature on the impact of restrictive environments on children's play experiences and on ways in which play may mitigate the adverse effects of such restrictions. Fifteen published, peer-reviewed studies were included, spanning various conditions and environments under which children faced restriction, including hospitalisation, juvenile and immigration detention, and displacement to a refugee camp. None were related to home confinement.

The first research question aimed to address how restrictive environments affect children's play; two key findings were identified. First, the included literature provides evidence that children's access to play can be impacted by children being placed under quarantine or isolation. Barriers to play were identified, such as unsafe spaces, scarcity of toys, lack of interaction with other children, and lack of time outdoors, and reports indicated that diminishing opportunities for play were associated with inactivity and boredom among children. Second, though frequency of play behaviours was recognised as an aspect of children's play that can be variable due to restricted conditions, only two studies examined this (Hollenbeck et al., 1980 [2]; Susman et al., 1981 [12]). Both studies were conducted in the context of hospitalisation, without a baseline measurement of play frequency, and the findings were contradictory. Thus it is not possible to draw definitive conclusions regarding changes in frequency of children's play during isolation.

Overall, there were relatively few studies characterising changes in the nature of children's play in restrictive environments. Most included studies were qualitative and varied greatly in terms of sample size, method of data collection, and the type of play referenced. At present, the field is lacking a thorough understanding and description of how children's play may be affected, or how it adapts or changes, to restrictive circumstances. This gap emphasises the pressing need to collect data from specific vulnerable populations, including children, during the current pandemic (Holmes et al., 2020). 
The second research question sought to inform how children's engagement in play behaviours may mitigate the impact of restriction on their health and wellbeing. Although the literature included in the review alludes to mechanisms through which play might support children during quarantine or isolation (e.g. via coping, social connectivity, self-expression), none of the studies tested these mechanisms explicitly. Most studies used qualitative data collection methods, which provided valuable insights on the perceived benefits of play and related activities under these conditions, especially from the perspective of children themselves. These findings are important in that they provide initial support for the hypothesis that play may have a role in attenuating the negative effects of restrictive environments and underscore the need for further research to test this hypothesis robustly. Specifically, there is a lack of evaluation research incorporating both qualitative and quantitative methodologies, that considers the effectiveness of play-based interventions for children in quarantine or isolated environments, or that examines the relationship between the degree to which children engage in play activities during isolation and their subsequent health and educational outcomes.

Certain studies utilised play specifically as a method or tool to engage children and young people. For instance, Kronick et al. (2018 [4]) used sand play as a narrative enquiry methodology to capture voices of migrant children and gain an understanding into their experiences of immigration detention. Playbased methods of data collection may serve as an effective, age-appropriate means of helping children share their perspectives on their lived experiences and express their feelings about it. Playful engagement in research can be particularly salient for younger children for whom play is a natural way in which they communicate and engage with their worlds (Thomas \& O'Kane, 1998).

Although we cannot draw strong conclusions regarding the therapeutic value of play based on the literature included in this review, we identified key themes pertaining to the pathways through which play may benefit or protect child outcomes during times of restriction. Findings illustrated that play and related activities provided children and young people with opportunities for socialisation. In studies of adolescents in juvenile detention centres, engagement in creative, expressive activities afforded opportunities for social connectivity and development of social skills, which is particularly important during the early adolescent developmental period (Waldrip, Malcolm, \& Jensen-Campbell, 2008). Children restricted to hospital environments also expressed a desire for more social connectivity via drawings depicting play areas, friends, shared spaces, and technological activities for play and communication (Lambert et al., 2014 [6]). Sociability is related to stress resilience in children (Zolkoski \& Bullock, 2012), and using play or related activities to promote socialisation may serve as a protective factor for children and young people in isolation. In the midst of school closures, home quarantine, closed play areas, and social distancing from other children throughout the COVID-19 pandemic, children have fewer natural opportunities for social connectivity. Children may welcome the advantages that technology confers for social connectivity in the absence of face-to-face interaction (Goldschmidt, 2020).

Our findings indicate that play also affords opportunities for expression. Creative and arts-based expressive activities (e.g. sand play, puppet play, writing, art, and music) were prominent in studies addressing our second research question. Evidence from the wider literature suggests that creative or expressive activities are often used in therapeutic or classroom settings, providing children with 
opportunities to communicate personal accounts, interact with others, and express emotion (Schaefer, 1993; Tyrer \& Fazel, 2014). For example, a systematic review of interventions conducted with refugee and asylum-seeking children suggests that creative arts-based interventions may reduce emotional and relational problems, as well as post-traumatic stress and depression symptoms, and improve wellbeing and self-esteem (Tyrer \& Fazel, 2014).

Notably, none of the included studies were designed to directly examine the impact of social distancing measures on play due to infectious disease outbreaks. Evidence shows that global infectious and respiratory diseases disproportionately affect populations in developing countries as compared to developed countries (Gupta \& Guin, 2010). Epidemics tend to emerge and persist in places of widespread poverty, and low-income countries often face a higher disease burden (Dupas, 2011; Griffiths, 2012). Our search strategy did not target grey literature, not published in peerreviewed, academic journals, which may report on data relevant to our research questions. For example, the views and voices of children affected by the Ebola crisis have been summarised in organisational reports by Save the Children (Kostelny et al., 2016; Risso-Gill \& Finnegan, 2015). Children experiencing restrictions due to school closure, social distancing, and household quarantine in Sierra Leone reported that they missed playing, seeing their friends, and that they felt unhappy, lonely, and trapped. Such information is pertinent to understanding how play might be important in alleviating negative aspects of children being in virus-related isolation.

Play is considered to be critical for children's physical and mental health, development, and wellbeing (Bergen, 2009; Lester \& Russell, 2010), and key global organisations such as UNCRC have highlighted the importance of children's right to play. However, in times of crises, the value of children's play is often overlooked (UNCRC, 2013). Under conditions of social restriction, there are likely to be changes to the nature of play as well as diminished opportunities for play engagement. For example, emerging, preliminary unpublished data from South Korea revealed that $94 \%$ of surveyed parents reported that their children's use of play and sports facilities had decreased during the current COVID-19 pandemic (see Guan et al., 2020). Emerging qualitative data from researchers in Italy states that $43 \%$ of parents surveyed reported that their child seemed more listless toward activities they were doing before the pandemic, including playing, studying and gaming (see Pisano, Galimi, \& Cerniglia, 2020). In order to improve our collective understanding of how to appropriately care for children during this, and future, health crises, there is a need to investigate how the current pandemic may impact children's opportunities for play and to describe changes in the quality and nature of children's play experiences within the context of social isolation and quarantine.

\section{Strengths and Limitations of the Rapid Review}

\section{Limitations}

There are inherent limitations when conducting a review in a short timeframe. It is possible that a broader search strategy would have yielded additional relevant research. Additionally, including the systematic searching of grey literature might have brought forth research regarding children in quarantine as a result of widespread infectious diseases or pandemics. Further deliberate, more systematic searching may also have produced literature addressing online play or games, which is not only a salient type of play for many adolescents, but is also likely to be particularly relevant to at-home play behaviours for children of the current generation. Similarly, this limitation may also apply to 
search terms relating to infectious diseases and pandemics, as none of the studies that were included in the analysis for the current review investigated quarantine as a result of an infectious disease.

In many of the studies we identified, factors related to the cause of restriction may have influenced results and limited our ability to generalise them to the current pandemic. For example, in a study of children isolated for cancer treatment, the authors noted that some observed behaviour change, including play behaviour, could have been related to drug toxicity (Susman et al., 1981 [12]). Similarly, studies exploring play in juvenile detention often reference characteristics or past experiences of the participants such as drug use and violence (e.g. Winn, 2012 [15]), which could impact on play experiences. These factors limit the generalisability of these studies' findings when considering them in the context of the current lockdown restrictions.

\section{Strengths}

Our broad definition of play (UNCRC, 2013) and related activities allowed for a wide lens through which we could consider the various types of activities that can be encompassed within the concept of play, depending on a child's age and circumstances. This could be instructive for others with a shared interest in conceptualising the ways in which quarantine may impact children's play.

Before conducting our search, we shared our proposed protocol via OSF to engage in an open consultation process with other academic researchers working in this area. This process allowed us to iteratively develop and refine our search terms, inclusion criteria, and protocol before conducting our final review. We believe that adhering to open science practices benefitted how we initiated and conducted this review: collating information that could be pertinent to policy and decision-making on behalf of children during the current pandemic necessitated both a swift and thorough procedure that had opportunities for peer review.

\section{Conclusions \& Next Steps}

This rapid review describes the literature regarding the impact of quarantine or other isolating circumstances on children's play behaviours and how play might mitigate resulting adverse effects on children's health outcomes. There remains significant gaps in understanding how play is affected by and influences children's health and education during times of restriction, especially during lockdown conditions due to an infectious disease outbreak. In particular, the literature examining how play might mitigate the impact of quarantine and isolation on children's health and educational outcomes was limited in quality and scope. Findings did indicate that children's access to play can be impacted by restrictive situations, though in the context of the current health crisis, children are not explicitly prevented from playing; rather, it is likely that play behaviours have needed to alter and adapt in light of the lockdown environment, in terms of reduced access to peers and resources such as playgrounds both in community and school environments. As such, while there are strong reasons to believe that the frequency of children's play behaviours would also change as a result of being in a state of lockdown, the dearth of available research does not allow for a substantial claim to be made in this regard. The evidence identified in this review established key themes alluding to potential pathways through which play may support children during isolation, although none directly examined these relationships. It is vital that we prioritise high-quality research that directly investigates play during restrictive and lockdown conditions. 
Notably absent from this literature search was research that investigated play and quarantine in longterm, disease-outbreak-related situations that could provide insights regarding the integrity of play amidst the current pandemic. This gap emphasises the pressing need to collect data from children directly in the context of other restrictive situations. It is imperative that children are given a voice and, critically, that their voices are listened to and valued. Future research that could guide both policy and practice could include studies that:

- Engage children directly, soliciting their perceptions, opinions, and priorities about their play experiences during lockdown restrictions

- Compare contexts where restrictions to play are lifted at different times (e.g. access to schools, playgrounds, eased social distancing regulations, etc.) and/or examine the impact of policies that allow changes to play opportunities (e.g., where families can isolate together)

- Identify families' expressed priorities and needs regarding play, and evaluate strategies or interventions to achieve this

- Identify the impact of recent large-scale initiatives to support play in crisis situations (e.g. BRAC Play Labs; PlayMatters)

Acknowledging the importance of play in moments of crisis is a critical component in understanding how children's worlds can be affected by quarantine, isolation, or other environmental restrictions. This sort of evidence base could help to guide policymakers as they navigate decision making around the imminent post-lockdown state, future restrictions, and new outbreaks. 


\section{Appendix A: Defining terms}

* Quarantine and related restricted environments: Extended state of living where children have limited movement (e.g. from home or hospital) because of restrictions by the government or medical advice, or other factors beyond their own control.

† Play and related activities: In accordance with the language put forth by the UNCRC, Article 31 states the rights of all children to "...rest and leisure, to engage in play and recreational activities appropriate to the age of the child and to participate freely in cultural life and the arts." The Committee further articulates what constitutes leisure, play, and recreational activities in General Comment No. 17:

Children's play is any behaviour, activity or process initiated, controlled and structured by children themselves; takes place whenever and wherever opportunities arise. Caregivers may contribute to the creation of environments in which play takes place, but play itself is noncompulsory, driven by intrinsic motivation and undertaking for its own sake, rather than a means to an end. Play involves the exercise of autonomy, physical, mental or emotional activity, and has the potential to take infinite forms, either in groups or alone. These forms will change and be adapted throughout the course of childhood. The key characteristics of play are fun, uncertainty, challenge, flexibility and non-productivity. Together, these factors contribute to the enjoyment it produces and the consequent incentive to continue to play. While play is often considered non-essential, the Committee reaffirms that it is a fundamental and vital dimension of the pleasure of childhood, as well as an essential component of physical, social, cognitive, emotional and spiritual development. Children's play also includes leisure activities (free, unobligated time without formal education, work, or responsibilities) and recreational activities (consisting of experiences such as participation in music, art, crafts, community engagement, clubs, sports, games, hiking and camping, pursuing hobbies) that are chosen voluntarily and discretionary by the child him or herself. 
Appendix B: Search syntax

(A) Population of interest:

(child* OR adolescen* OR teenage* OR (paediatric OR pediatric) OR youth OR "young people" OR infan* OR toddler OR preschool OR "school age")

AND

(B) Quarantine and restricted environments:

(quarantine OR "social distancing" OR "social restriction" $O R$ "patient isolation" OR confine* OR (lockdown OR "lockdown" OR curfew) OR "deprivation-isolation" OR "protect* environment" OR detention OR incarceration)

\section{AND}

(C) Play and related activities:

(play* OR (art OR arts OR "arts-based") OR sport* OR exercise OR "outdoor activities" OR "outdoor spaces" OR exploration OR discovery OR toys OR games OR "social media" OR ("free play" OR "free-play") OR "adult-directed activities" OR drawing OR crafts OR reading OR "book sharing" OR danc* OR sing* OR fun) OR drama* OR imagin*)

Optional terms included in iterative search process:

(A) OR (famil* OR student* OR kindergarten*)

(B) AND (epidemic OR outbreak OR crisis OR pandemic OR separation OR "social isolation" OR "extreme weather" OR flood OR ice storm OR pandemic OR disaster OR "natural disaster" OR war OR "war zone" OR "conflict area" OR (refuge* OR immigra*) OR (SARS OR "severe acute respiratory syndrome") OR (H1N1 OR "swine flu" OR "swine influenza") OR (MERS OR "Middle East respiratory syndrome" OR "Middle East Respiratory Syndrome Coronavirus" OR "MERS-CoV") OR "influenza pandemic" OR "equine influenza" OR "infectious disease" OR virus OR "viral infection" OR "contagious disease" OR (coronavirus* OR coronavirus infections OR COVID-19 OR SARS-Cov-2)) 
Figure I: PRISMA Flowchart

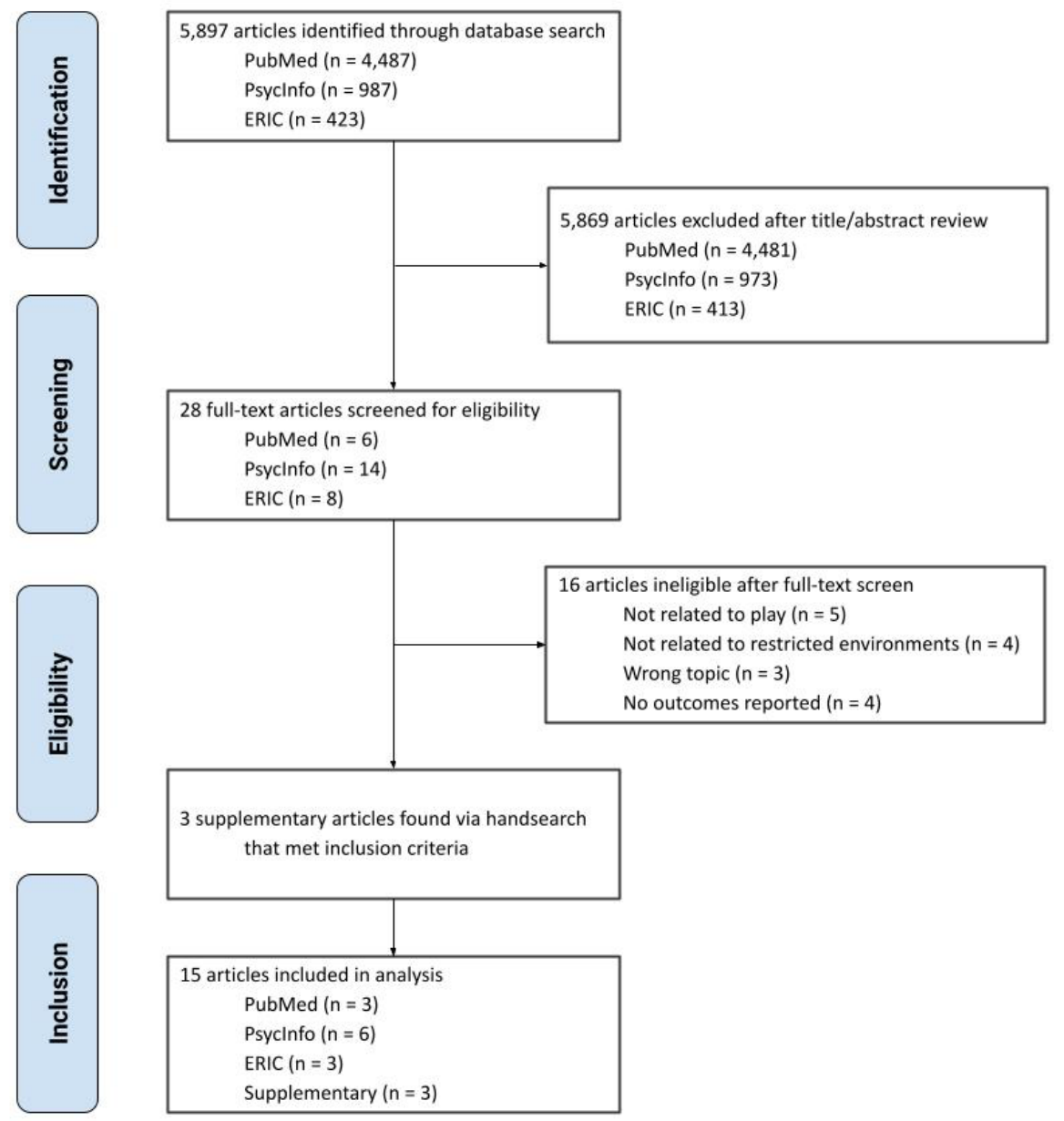


Table 1: Study characteristics

\begin{tabular}{|c|c|c|c|c|c|c|c|c|}
\hline & Study & Country & Design & Measures & $\begin{array}{c}\text { Participant } \\
\text { age }\end{array}$ & $\begin{array}{c}\text { Sample } \\
\text { Size }\end{array}$ & $\begin{array}{l}\text { Restriction } \\
\text { setting }\end{array}$ & $\begin{array}{c}\text { Type of } \\
\text { play }\end{array}$ \\
\hline 1 & $\begin{array}{l}\text { Brodsky } \\
(1989)^{*}\end{array}$ & Israel & Qualitative & NA & $4-10 y$ & 4 & Hospital & Music \\
\hline 2 & $\begin{array}{l}\text { Hollenbeck et } \\
\text { al. (1980) }\end{array}$ & US & Quantitative & Observation & $18 m-4 y$ & 4 & Hospital & Undefined \\
\hline 3 & $\begin{array}{l}\text { Kronick et al. } \\
(2015)^{*}\end{array}$ & Canada & Qualitative & $\begin{array}{l}\text { Ethnographic } \\
\text { observation, } \\
\text { interviews }\end{array}$ & $6-18 y$ & $\begin{array}{l}20 \\
\text { families }\end{array}$ & $\begin{array}{l}\text { Immigration } \\
\text { detention }\end{array}$ & Undefined \\
\hline 4 & $\begin{array}{l}\text { Kronick et al. } \\
(2018)\end{array}$ & Canada & Qualitative & $\begin{array}{l}\text { Interviews and } \\
\text { observations }\end{array}$ & $3-13 y$ & 10 & $\begin{array}{l}\text { Immigration } \\
\text { detention }\end{array}$ & Sand play \\
\hline 5 & $\begin{array}{l}\text { Kuntz et al. } \\
(1996)^{*}\end{array}$ & US & Qualitative & Case studies & $0-7 y$ & 2 & Hospital & Toy play \\
\hline 6 & $\begin{array}{l}\text { Lambert et al. } \\
(2014)\end{array}$ & Ireland & Qualitative & $\begin{array}{l}\text { Semi-structured } \\
\text { interviews and art } \\
\text { activities }\end{array}$ & $5-8 y$ & 55 & Hospital & $\begin{array}{l}\text { Art, } \\
\text { discussion }\end{array}$ \\
\hline 7 & $\begin{array}{l}\text { Linn et al. } \\
(1996)\end{array}$ & US & Qualitative & Puppet play & $4-6 y$ & 1 & Hospital & $\begin{array}{l}\text { Puppet } \\
\text { play }\end{array}$ \\
\hline 8 & $\begin{array}{l}\text { Mares et al. } \\
(2002)\end{array}$ & Australia & Qualitative & NA & $5 m-21$ y & $\begin{array}{l}2 \\
\text { families }\end{array}$ & $\begin{array}{l}\text { Immigration } \\
\text { detention }\end{array}$ & Undefined \\
\hline 9 & $\begin{array}{l}\text { Pytash } \\
(2013)\end{array}$ & US & Qualitative & $\begin{array}{l}\text { Case study, } \\
\text { observations and } \\
\text { interviews }\end{array}$ & $17 y$ & 1 & $\begin{array}{l}\text { Juvenile } \\
\text { detention }\end{array}$ & $\begin{array}{l}\text { Reading, } \\
\text { writing }\end{array}$ \\
\hline 10 & $\begin{array}{l}\text { Robb } \\
(2000)\end{array}$ & US & Quantitative & $\begin{array}{l}\text { Observation, } \\
\text { Affective Face Scale }\end{array}$ & $4-11 y$ & 10 & Hospital & $\begin{array}{l}\text { Music, } \\
\text { varied }\end{array}$ \\
\hline 11 & $\begin{array}{l}\text { Shea and Siu } \\
(2016)\end{array}$ & US & $\begin{array}{l}\text { Mixed } \\
\text { methods }\end{array}$ & $\begin{array}{l}\text { Study specific survey, } \\
\text { observation, analysis } \\
\text { of worksheet/craft }\end{array}$ & $14-18 y$ & 295 & $\begin{array}{l}\text { Juvenile } \\
\text { detention }\end{array}$ & Varied \\
\hline 12 & $\begin{array}{l}\text { Susman et al. } \\
(1981)\end{array}$ & US & Quantitative & Observation & $18 m-21 y$ & 23 & Hospital & Varied \\
\hline 13 & $\begin{array}{l}\text { Venable } \\
(2005)\end{array}$ & US & Qualitative & Exit survey & $\begin{array}{l}16 y \\
\text { (mean age) }\end{array}$ & $\begin{array}{l}\text { Not } \\
\text { specified }\end{array}$ & $\begin{array}{l}\text { Juvenile } \\
\text { detention }\end{array}$ & Art \\
\hline 14 & $\begin{array}{l}\text { Veronese et } \\
\text { al. (2018) }\end{array}$ & $\begin{array}{l}\text { Occupied } \\
\text { Palestinian } \\
\text { Territories }\end{array}$ & Qualitative & $\begin{array}{l}\text { Thematic a nalysis of } \\
\text { children's art/writing }\end{array}$ & $6-15 y$ & 122 & $\begin{array}{l}\text { Refugee } \\
\text { camps }\end{array}$ & $\begin{array}{l}\text { Art, } \\
\text { writing }\end{array}$ \\
\hline 15 & $\begin{array}{l}\text { Winn } \\
\text { (2012) }\end{array}$ & US & Qualitative & $\begin{array}{l}\text { Thematic analysis of } \\
\text { adolescent girls' } \\
\text { writing }\end{array}$ & $14-17 y$ & $\begin{array}{l}\text { Not } \\
\text { specified }\end{array}$ & $\begin{array}{l}\text { Juvenile } \\
\text { detention }\end{array}$ & Writing \\
\hline
\end{tabular}

* Indicates article found via handsearching

Footnote: All studies met inclusion criteria for involving children $\leq 18$ years, though in two studies $[8,12]$ the maximum age of participants was 21 years. 


\section{References}

Armitage, R., \& Nellums, L. B. (2020). Considering inequalities in the school closure response to COVID-19. The Lancet Global Health, 8(5), e644. Retrieved from https://www.ncbi.nlm.nih.gov/pmc/articles/PMC7195275/pdf/main.pdf

Bergen, D. (2009). Play as the Learning Medium for Future Scientists, Mathematicians, and Engineers. American Journal of play, 1(4), 413-428.

Berkman, B. E. (2008). Mitigating pandemic influenza: The ethics of implementing a school closure policy. Journal of Public Health Management and Practice, 14(4), 372-378. Retrieved from $<$ Go to $|S|>$ ://WOS:000256855500010

Brodsky, W. (1989). Music therapy as an intervention for children with cancer in isolation rooms. Music Therapy, 8(1), 17-34.

Brooks, S. K., Webster, R. K., Smith, L. E., Woodland, L., Wessely, S., Greenberg, N., \& Rubin, G. J. (2020). The psychological impact of quarantine and how to reduce it: rapid review of the evidence. Lancet, 395(10227), 912-920. doi:10.1016/S0140-6736(20)30460-8

Chatterjee, S. (2018). Children's Coping, Adaptation and Resilience through Play in Situations of Crisis. Children, Youth and Environments, 28(2), 119-145.

Cohen, E. (2018). Political Violence (War and Terrorism) and Children's Play. In P. K. Smith \& J. L. Roopnarine (Eds.), The Cambridge Handbook of Play: Developmental and Disciplinary Perspectives (pp. 649-664). Cambridge: Cambridge University Press.

Dupas, P. (2011). Health behavior in developing countries. Annu. Rev. Econ., 3(1), 425-449.

Fore, H. (2020). Don't let children be the hidden victims of COVID-19 pandemic [Press release]. Retrieved from https://www.unicef.org/press-releases/dont-let-children-be-hidden-victimscovid-19-pandemic

Ganann, R., Ciliska, D., \& Thomas, H. (2010). Expediting systematic reviews: methods and implications of rapid reviews. Implementation Science, 5, 10-19. doi:Artn 56

10.1186/1748-5908-5-56

Goldschmidt, K. (2020). The COVID-19 pandemic: Technology use to support the wellbeing of children. Journal of Pediatric Nursing.

Griffiths, S. (2012). Chapter 1: Why research infectious diseases of poverty. Global report for research on infectious diseases of poverty, 1-34.

Guan, H., Okely, A. D., Aguilar-Farias, N., del Pozo Cruz, B., Draper, C. E., El Hamdouchi, A., . . Kontsevaya, A. (2020). Promoting healthy movement behaviours among children during the COVID-19 pandemic. The Lancet Child \& Adolescent Health.

Gupta, I., \& Guin, P. (2010). Communicable diseases in the South-East Asia Region of the World Health Organization: towards a more effective response. Bulletin of the World Health Organization, 88, 199-205. Retrieved from https://www.ncbi.nlm.nih.gov/pmc/articles/PMC2828785/pdf/09-065540.pdf

Hollenbeck, A. R., Susman, E. J., Nannis, E. D., Strope, B. E., Hersh, S. P., Levine, A. S., \& Pizzo, P. A. (1980). Children with Serious Illness: Behavioural Correlates of Separation and Isolation. Child Psychiatry and Human Development, 11(1), 3-11.

Holmes, E. A., O'Connor, R. C., Perry, V. H., Tracey, I., Wessely, S., Arseneault, L., . . Everall, I. (2020). Multidisciplinary research priorities for the COVID-19 pandemic: a call for action for mental health science. The Lancet Psychiatry.

Hutchins, S. S., Truman, B. I., Merlin, T. L., \& Redd, S. C. (2009). Protecting Vulnerable Populations From Pandemic Influenza in the United States: A Strategic Imperative. American Journal of Public Health, 99, S243-S248. doi:10.2105/Ajph.2009.164814

International Play Association. (2017). Access to Play for Children in Situations of Crisis. Retrieved from http://ipaworld.org/wp-content/uploads/2017/07/IPA-A4-ACCESS-TO-PLAY-INSITUATIONS-OF-CRISIS-TOOLKIT-LR.pdf 
International Play Association. (2020). The importance of playing during a crisis. Retrieved from http://ipaworld.org/wp-content/uploads/2020/04/APC1-The-importance-of-playing-duringa-crisis.pdf

Kostelny, K., Lamin, D., Manyeh, M., Ondoro, K., Stark, L., Lilley, S., \& Wessells, M. (2016). Worse than the War': An Ethnographic Study of the Impact of the Ebola Crisis on Life. Sex, Teenage Pregnancy, and a Community-Driven Intervention in Rural Sierra Leone, London: Save the Children.

Kronick, R., Rousseau, C., \& Cleveland, J. (2015). Asylum-seeking children's experiences of detention in Canada: A qualitative study. Am J Orthopsychiatry, 85(3), 287-294. doi:10.1037/ort0000061

Kronick, R., Rousseau, C., \& Cleveland, J. (2018). Refugee children's sandplay narratives in immigration detention in Canada. European Child \& Adolescent Psychiatry, 27(4), 423-437. doi:10.1007/s00787-017-1012-0

Kuntz, N., Adams, J. A., Zahr, L., Killen, R., Cameron, K., \& Wasson, H. (1996). Therapeutic play and bone marrow transplantation. J Pediatr Nurs, 11(6), 359-367. doi:10.1016/S08825963(96)80080-7

Lambert, V., Coad, J., Hicks, P., \& Glacken, M. (2014). Social spaces for young children in hospital. Child: Care, Health and Development, 40(2), 195-204. doi:10.1111/cch.12016

Landrigan, P. J. (2005). Children as a vulnerable population (Reprinted from the European Journal of Oncology Library, vol 2, 2003). Human and Ecological Risk Assessment, 11(1), 235-247. doi:10.1080/10807030590920051

Lester, S., \& Russell, W. (2010). Children's Right to Play: An Examination of the Importance of Play in the Lives of Children Worldwide. Working Papers in Early Childhood Development, No. 57: ERIC.

Linn, S., Beardslee, W., \& Patenaude, A. F. (1996). Puppet Therapy with Pediatric Bone Marrow Transplant Patients. Journal of Pediatric Psychiatry, 11(1), 37-46.

Loades, M. E., Chatburn, E., Higson-Sweeney, N., Reynolds, S., Shafran, R., Brigden, A., . . Crawley, E. (2020). Rapid Review: The impact of social isolation and loneliness on the mental health of children and adolescents in the context of COVID-19. Retrieved from osf.io/p8q3d

Mares, S., Newman, L., Dudley, M., \& F., G. (2002). Seeking Refuge, Losing Hope: Parents and Children in Immigration Detention. Australasian Psychiatry, 10(2), 91-96.

Nijhof, S. L., Vinkers, C. H., van Geelen, S. M., Duijff, S. N., Achterberg, E. J. M., van der Net, J., . . Lesscher, H. M. B. (2018). Healthy play, better coping: The importance of play for the development of children in health and disease. Neurosci Biobehav Rev, 95, 421-429. doi:10.1016/j.neubiorev.2018.09.024

Pisano, L., Galimi, D., \& Cerniglia, L. (2020, April 13). A qualitative report on exploratory data on the possible emotional/behavioral correlates of Covid-19 lockdown in 4-10 years children in Italy. doi:https://doi.org/10.31234/osf.io/stwbn

Pytash, K. E. (2013). " I'm a reader": Transforming Incarcerated Girls' Lives in the English Classroom. English Journal, 67-73.

Ramchandani, P. (2020, 8 April). Covid-19: We can ward off some of the negative impacts on children. NewScientist(3277). Retrieved from https://institutions.newscientist.com/article/mg24532773-000-covid-19-we-can-ward-offsome-of-the-negative-impacts-on-children/

Ren, X. (2020). Pandemic and lockdown: a territorial approach to COVID-19 in China, Italy and the United States. Eurasian Geography and Economics, 1-12.

Risso-Gill, I., \& Finnegan, F. (2015). Children's Ebola recovery assessment: Sierra Leone. Save the Children Fund. World Vision International, Plan International, UNICEF.

Robb, S. L. (2000). The Effect of Therapeutic Music Interventions on the Behavior of Hospitalized Children in Isolation: Developing a Contextual Support Model of Music Therapy. Journal of Music Therapy, 37(2), 118-146. Retrieved from https://pubmed.ncbi.nlm.nih.gov/10932125/ 
Schaefer, C. E. (1993). The therapeutic powers of play: Jason Aronson.

Shea, C.-K., \& Siu, A. M. H. (2016). Engagement in Play Activities as a Means for Youth in Detention to Acquire Life Skills. Occupational Therapy International, 23(3), 276-286. doi:10.1002/oti.1432

Susman, E. J., Hollenbeck, A. R., Nannis, E. D., Strope, B. E., Hersh, S. P., Levine, A. S., \& Pizzo, P. A. (1981). A Prospective Naturalistic Study of the Impact of an Intensive Medical Treatment on the Social Behavior of Child and Adolescent Cancer Patients. Journal of Applied Developmental Psychology, 2, 29-47.

Thomas, N., \& O'Kane, C. (1998). The ethics of participatory research with children. Children \& society, 12(5), 336-348.

Tyrer, R. A., \& Fazel, M. (2014). School and Community-Based Interventions for Refugee and Asylum Seeking Children: A Systematic Review (vol 9, e89359, 2014). Plos One, 9(5). doi:ARTN e97977

10.1371/journal.pone.0097977

United Nations. (2020). Policy Brief: The Impact of COVID-19 on children. Retrieved from https://unsdg.un.org/sites/default/files/2020-04/160420 Covid Children Policy Brief.pdf

United Nations Committee on the Rights of the Child (UNCRC). (2013). General comment No. 17 on the right of the child to rest, leisure, play, recreational activities, cultural life and the arts (art. 31). Retrieved from https://www.refworld.org/docid/51ef9bcc4.html

Venable, B. B. (2005). At-risk and in-need: Reaching juvenile offenders through art. Art Education, 58(4), 48-53.

Veronese, G., Cavazzoni, F., \& Antenucci, S. (2018). Narrating hope and resistance: A critical analysis of sources of agency among Palestinian children living under military violence. Child Care Health Dev, 44(6), 863-870. doi:10.1111/cch.12608

Waldrip, A. M., Malcolm, K. T., \& Jensen-Campbell, L. A. (2008). With a Little Help from Your Friends: The Importance of High-quality Friendships on Early Adolescent Adjustment. Social Development, 17(4), 832-852. doi:10.1111/j.1467-9507.2008.00476.x

Winn, M. T. (2012). The politics of desire and possibility in urban playwriting:(Re) reading and (re) writing the script. Pedagogies: An International Journal, 7(4), 317-332.

World Health Organization. (2020). Coronavirus disease (COVID-2019) situation reports. Retrieved from https://www.who.int/emergencies/diseases/novel-coronavirus-2019/situation-reports

Xie, X., Xue, Q., Zhou, Y., Zhu, K., Liu, Q., Zhang, J., \& Song, R. (2020). Mental Health Status Among Children in Home Confinement During the Coronavirus Disease 2019 Outbreak in Hubei Province, China. JAMA pediatrics.

Yogman, M., Garner, A., Hutchinson, J., Hirsh-Pasek, K., Golinkoff, R. M., Committee On Psychosocial Aspects Of, C., ... Media. (2018). The Power of Play: A Pediatric Role in Enhancing Development in Young Children. Pediatrics, 142(3). doi:10.1542/peds.2018-2058

Zolkoski, S. M., \& Bullock, L. M. (2012). Resilience in children and youth: A review. Children and Youth Services Review, 34(12), 2295-2303. doi:10.1016/j.childyouth.2012.08.009 